\title{
ELS FORNS DE VIDRE A BARCELONA I LA SEVA RODALIA (SEGLES XIV-XVI)
}

\author{
KILNS OF GLASS IN BARCELONA AND ITS SURROUNDINGS \\ (14th-16th CENTURIES)
}

\author{
Sílvia CAÑELlas I MARTíNeZ \\ M. CARME DOMÍNGUEZ RODÉS
}

Resum: Malgrat les disposicions municipals medievals sobre la prohibició d'instal lar forns de vidre dins les ciutats, alguns establiments van estar actius durant un temps considerable. La ciutat de Barcelona n'és un clar exemple. El present article se centra en les dades documentals trobades en els arxius barcelonins. A la ciutat de Barcelona, el forn de vidre de Viladalls va funcionar des de les primeries del segle XIV fins a finals del XV. Altres forns de vidre van néixer a l'entorn de la ciutat o vinculats a mestres vidriers procedents d'aquesta. És el cas dels forns de Mallorca (1352), Badalona (1360), St. Pere de Bigues (1407-1513), St. Vicenç de Vallromanes (1429-84) i Montcada (148689). Al segle $X V$, un nou forn de vidre, situat al Pla d'en Llull, tingué l'exclusivitat en la producció de vidre a Barcelona, situació que es va mantenir fins a mitjan segle XVI.

Paraules clau: Vidre; Forn de vidre; Barcelona, Vidriers, Edat Mitja.

\begin{abstract}
In spite of the municipal regulations of the Middle Ages about the prohibition of setting up kilns of glass in the cities, some remained for a long time. Barcelona is a clear example. This article is about our kilns and the information has been taken from the Archives of Barcelona. The kiln of Viladalls worked in Barcelona from the early 14th century to the end of the 15th century. Other kilns of glass could be found on the outskirts of the city or some were linked with some glaziers masters of Barcelona who worked here. We can see it in the kilns of Mallorca (1352), Badalona (1360), St. Pere de Bigues (1407-1513), St. Vicenç de Vallromanes (1439-84), and Montcada (148689). A new kiln set up in Pla d'en Llull, Barcelona, in the 15th century, was the only one which had the Royal permission until the mid $16^{\text {th }}$ century.
\end{abstract}

Keywords: Glass; Kilns of glass; Barcelona; Glaziers; Middle Ages.

\section{SUMARI}

1. Els forns de vidre a Barcelona al segle XIV i principis del XV.- 2. El forn de Viladalls: 2.1. El forn de vidre de Viladalls en els seus inicis. 2.2. El forn de Viladalls al segle XV.- 3. Altres forns dels segles XIV i XV (1352-1505): 3.1. Instal-lació d'un forn de vidre a Mallorca (1352). 3.2. Instal'lació del forn de vidre de Badalona (1360). 3.3. Dades relacionades amb el forn de vidre de Sant Pere de Bigues (1407-1513). 3.4. El forn de vidre de Sant Vicenç de Vallromanes (1429-1484). 3.5. Els forns de vidre de Montcada (1486-1489).- 4. El forn de vidre del Pla

\footnotetext{
${ }^{1}$ Col-laboradores del Corpus Vitrearum Medii Aevi Catalunya (Institut d'Estudis Catalans. Barcelona).
} 
d'en Llull (1453-1640): 4.1. Bartomeu Llorenç i el forn de vidre del Pla d'en Llull (14531492). 4.2. El vidrier Mateu Llorenç. El tombant del segle XV al XVI. 4.3. L'arrendament de principis del segle XVI. 4.4. El segle XVI i següents. 4.5. Tancament del forn del Pla d'en Llull.- Conclusió.

\section{ELS FORNS DE VIDRE A BARCELONA AL SEGLE XIV I PRINCIPIS DEL XV}

A Barcelona, tal com passà a altres ciutats, les disposicions de les institucions dels diferents governs del primer quart de segle XIV, parlen de la prohibició de tenir forns de vidre dins la ciutat.

En el cas de Girona, la prohibició de fabricar cendra i vidre dins la ciutat, vegueria i bisbat, data del primer d'octubre de l'any 1322 i fou promulgada per ordre reial de Jaume II, a causa de la carestia de llenya ${ }^{2}$. L'any 1329 es revocaren de nou tots els permisos per fabricar vidre dins la mateixa ciutat ${ }^{3}$. Es concediren, en canvi, permisos per instal-lar forns fora ciutat com l'obtingut, el juliol de 1331, pel vidrier Bernat Roger, qui situaria el seu forn a tres llegües de Girona ${ }^{4}$. No se sap si altres vidriers tingueren més fortuna en aconseguir situar els seus forns dins la ciutat per aquelles dates, però hi ha la certesa que a finals del segle següent existia, com a mínim, un forn de vidre dins la ciutat de Girona, i que es trobava al carrer del Porquer. Per aquest forn, el vidrier gironí Benet Gràcia pagà al rei el cens anual corresponent a l'any $1482^{5}$.

A Barcelona, la prohibició fou dictada pel Consell de Cent l'any 1323, però sembla que la decisió no fou presa amb unanimitat per totes les institucions i fou ràpidament contravinguda i abandonada ${ }^{6}$.

Així, malgrat la prohibició d'instal·lar forns de vidre dins la ciutat, se sap que a Barcelona se seguí amb la producció de vidres i, per tant, amb el funcionament del forn o dels forns especialitzats en aquesta producció, des de dates properes al mateix any de la disposició prohibitòria.

En concret, parlarem aquí de dos forns dins la ciutat i d'altres que s'hi relacionaren. Dels dos ubicats a la ciutat, el més antic era situat al quarter del $\mathrm{Pi}$, mentre l'altre, ja de mitjans del segle XV, es trobava al Pla d'en Llull. Entre els dos cobriren una cronologia que va comprendre, com a mínim i de forma continuada, des de l'any 1325 fins al 1605 i van treballar, en els seus

\footnotetext{
${ }^{2}$ ACA, Cancelleria, reg. 222, f. 91 r. (AHCG, Original en pergamí núm. 776).

${ }^{3} \mathrm{ACA}$, Cancelleria, reg. 480, f. 119 r. En el document s'explica que la llenya és necessària per fer galeres i per a altres usos.

${ }^{4}$ ACA, Cancelleria, reg. 483, f. 249 r. na.

${ }^{5}$ ACA, Reial Patrimoni, Batllia, vol. 327, f. 1961 r. Explica que la propietat havia estat anteriorment del mercader Ferrer de Comelles.

${ }^{6}$ AHCB, Manuscrits, "Rúbrica d'ordinacions 1477", L-38. f. 193 r. Esmentat per gran part de la bibliografia anterior que ha tractat el tema del vidre a Catalunya, el text original no es conserva $i$ el coneixem per una còpia de 1477 de les ordinacions anteriors. Entre aquestes es pot llegir: "Que algú no gos obrar de vidre en ciutat ne dins lo territori de aquella per rehó del dampnatge que se.n segueix" i s'esmenta la referència d'on s'extreu la dada, del llibre de l'any
} 
respectius moments i per desig exprés del rei, en exclusivitat dins la ciutat de Barcelona i la seva rodalia ${ }^{7}$.

La bibliografia que se centra en qüestions referides als forns de vidre, comenta la importància del vidre medieval i modern català, el compara amb el de Venècia $\mathrm{i}$ el considera entre els de més qualitat ${ }^{8}$. Entre les concessions de forns de vidre fetes en el segle XIV i mencionades pels estudiosos en la matèria, cal destacar la que atorgà el rei Pere el Cerimoniós a Bernat Desmunt l'any $1346^{9}$.

El document mostra que les llicències promogudes pel rei contravenien, en alguns casos, amb plena consciència, les ordenacions del Consell de $\mathrm{Cent}^{10}$. El text ens diu que el rei havia donat llicència per a la instal·lació, dins Barcelona, d'un forn de vidre a Bernat Desmunt, vidrier de Barcelona, però això contravenia les ordres dels consellers de la ciutat i els privilegis atorgats a Barcelona. S'explica que s'havien fet enderrocar altres forns de vidre que tenien els mateixos drets que aquest. Desmunt aconseguí, però, un acord amb el Consell de la ciutat: els consellers acceptaven que dit vidrier construís el seu forn de vidre imposant-li algunes condicions referides a la llenya que calia per al seu funcionament. Així, s'acordà que tota la llenya que es cremés, de dia o nit, fos de pi i procedent del Coll de Balaguer o de més lluny; o bé que vingués del Castell de Vacarisses, però no pas d'altres llocs. Si això no s'acomplia, el vidrier hauria de pagar una multa de 2.000 sous cada cop que infringís la norma. Si en algun moment els consellers consideraven que el forn era nociu per a la ciutat, podien fer-lo enderrocar. La llenya que es portés per al forn s'hauria de descarregar front la drassana o al moll del monestir de les Predicadores, o allà on els consellers assenyalessin. Si es contravenia aquesta condició, el vidrier hauria de pagar una multa de 1.000 sous cada vegada que això passés ${ }^{11}$.

${ }^{7} \mathrm{Com}$ veurem, tot i que l'exclusivitat del forn continua fins a l'any $1648 \mathrm{i}$ el pagament del cens es fa efectiu fins aquesta data, aquest no funcionava ja dins la ciutat, possiblement des de finals del segle anterior.

${ }^{8}$ Destaquem entre altres: Joan AINAUd I DE LASARTE, Cerámica y vidrio "Ars Hispaniae", vol. X, Ed. Plus Ultra, Madrid, 1952; Martine CAMIADE i Denis FONTAINE, Verreries. Verriers catalans. L'Albera, Palau del Vidre, Perpignan, Ed. Sources, Perpinyà, 2006; Ignasi DOMÉNECH I VIVES, El vidrio, Artes decorativas I, capitol IX, dins "Summa Artis. Historia General del Arte" vol. XLV, Espasa Calpe, Madrid 1999; Francisco DUSAY Y DE MARÍ, Memorias sobre los principios químicos del arte de fabricar vidrio (Leída el dia 25 de Enero de 1792 en la Real Academia de Ciencias Naturales y Artes de Barcelona), (Prefacio y transcripción del manuscrito original por Josep IGLESIAS), Real Academia de Ciencias y Artes de Barcelona, Barcelona, 1964. Josep GUDIOL RICART, Els vidres catalans, "Monumenta Cataloniae", vol. III, Editorial Alpha, Barcelona, 1936; Josep IGLESIAS, Pere Gil, S.I. (1551-1622) i la seva geografia de Catalunya, "Cuadernos de Geografía", núm. I, Barcelona. 1949; Anna OLIVER, Aportació al coneixement del vidre català medieval.' El taller de Sant Fost de Campsentelles (Vallès Oriental), tesina presentada a la Facultạt d'Histộria de la Universitat de Barcelona, gener de 1986; Luis PÉREZ BUENO, Vidrios y vidrieras, Editorial Alberto Martín, col-lecció "Àrtes decorativas españolas", Barcelona, 1942; Leopoldo PlANEll, Historia del gremio de vidrieros de luz y soplo de Barcelona. Vidrio. Historia, tradición y arte, 2 vols., Tipografía Emporium, Barcelona, 1948.; TheOPHILUs, De Diversis Artibus. The Various Arts, (s. XII), Thomas Nelsonaud Sons Ltd., Londres, 1961. pp. 26-60; Joan VALLS I PUEYO, Els forns de vidre i els vidriers, "Vacarisses. Balcó de Montserrat”, núm. 403-404 (març-abril 2002).

${ }^{9} \mathrm{El}$ nom d'aquest vidrier apareix també escrit com Bernat des Munt, dez Munt o de Monte.

${ }^{10} \mathrm{El}$ document en què ens basem va ser esmentat per J. GUDIOL, ob. cit., p. 32.

${ }^{11}$ ACA, Cancelleria, reg. 1678, "Gratiarum 3. Pere III", f. 71 r. 
Una altra dada referida al vidrier Bernat Desmunt el situa a Barcelona en el fogatge datat el dia 1 d'abril del $1374^{12}$. Altres referències el documenten exercint el seu ofici a Barcelona com a mínim fins a l'any $1408^{13}$.

\section{EL FORN DE VILADALLS}

\subsection{El forn de vidre de Viladalls en els seus inicis}

Una de les primeres notícies que s'han localitzat sobre forns de vidre als voltants de Barcelona, data del desembre del 1316. En el document és esmentat el vidrier de Barcelona Guillem Barceló per problemes relacionats amb la llenya que li calia per fer vidre ${ }^{14}$. La notícia, però, no aporta dades sobre la localització d'aquest forn. En canvi, un document posterior, de l'any 1325, menciona Guillem com a posseïdor de l'únic forn de vidre que hi havia dins la ciutat de Barcelona. L'any 1331, el rei refermava la concessió a Guillem Barceló i insistia en la condició de no cremar més de tres somades de llenya al dia ${ }^{15}$. L'abril del 1340, el mateix vidrier rebia un nou permís reial per al funcionament del seu forn de vidre, que continuava sent l'únic de la ciutat de Barcelona. Aquesta concessió per fer vidre en la seva propietat s'aplicaria a ell i als seus hereus o successors. La quantitat de llenya que es podia cremar havia augmentat, ara, fins a quatre somades al dia, cosa que parla de la creixent activitat del forn ${ }^{16}$.

Entre aquestes darreres dates i la renovació dels privilegis per part de Pere Barceló, passaren 30 anys en els quals no se saben quins entrebancs o alegries donà el forn. Es coneix, això sí, l'esmentada concessió del 1346 del forn de vidre a Bernat Desmunt. L'any 1370, l'herència dels béns de Guillem fou rebuda pel seu fill Pere Barceló, també vidrier, qui es féu càrrec del forn ${ }^{17}$. En el registre de la Cancelleria Reial que recull el document, s'explica que es tracta del forn per al qual el rei havia concedit permís a Guillem Barceló i que havia estat ratificat en les dues ocasions que hem esmentat: una l'any 1325 i l'altra el 1340. El forn estava situat en una propietat -no es diu exactament on- que tenia el difunt Guillem a Barcelona. La concessió fou feta, segons el rei i malgrat l'oposició dels consellers de la Ciutat, en benefici del conjunt de la població, ja que Barcelona no tenia cap altre forn de vidre i amb aquest s'oferia a la ciutat la producció de vidre que li calia. En el forn es podia coure vidre i fer vaixelles i altres artificis de vidre. El rei recordava

\footnotetext{
${ }^{12} \mathrm{AHCB}$, Consell de Cent, Sèrie XIX, núm. 1, vol. 2, f. 14 r.

${ }^{13}$ AHCB, Clavaria, Sèrie XI, núm. 24 (1400), f. 97 v.; núm. 26 (1401-1402), f. 93 r.; núm. 27 (1403-1404), ff. 65 v. i 207 v.; núm. $28-29$ (1405), f. 85 r.; núm. 32 (1408), f. 43 v.

${ }^{14} \mathrm{ACA}$, Cancelleria, reg. 213, f. 246 r.

${ }^{15} \mathrm{ACA}$, Cancelleria, reg. 483, f. 253 r.

${ }^{16} \mathrm{ACA}$ Cancelleria, reg. 869, ff. 223 v.-224 r. En aquest escrit es fa referència a un permís anterior, de l'any 1325 .

${ }^{17}$ ACA, Cancelleria, reg. 918, "Gratiarum 44. Pere III", f. 140 v.
} 
i confirmava que els successors de Guillem, en aquest cas Pere Barceló, i també els successors d'aquest últim, podien tenir a perpetuïtat aquesta concessió i que el límit de consum diari de llenya seguia sent el de quatre somades de llenya grossa.

Només quatre mesos després, l'agost del 1370, en el nou atorgament reial, es parla per primera vegada d'exclusivitat. El rei no només es manifestava en favor del forn de vidre de Pere Barceló, sinó que deia que aquest forn produïa, des de temps enrere, obra en vidre de bona qualitat, de fi i clar vidre i que en resultaven productes de formes ben diverses i de bon preu. I tot això fins a tal punt que resultaven superflus altres forns similars dins la ciutat i en dues llegües a l'entorn. A més, hi afegia, que d'existir aquests, suposarien un consum innecessari de llenya. Es prohibien, així, altres instal-lacions similars i es parlava de la imposició de multes a qui contravingués això. El preu que es cobrà per l'establiment en exclusiva fou de 50 maravedís d'or ${ }^{18}$.

Per aquestes dates la documentació no és clara sobre la situació exacta del forn dins la ciutat. I no ho és fins a principis del segle XV, quan se'l pot situar, sense problemes, tocant l'actual Rambla, a l'alçada de la plaça Reial. En aquell moment se situava al costat de Viladalls, és a dir, al costat del prostíbul de la ciutat. Sembla que aquesta localització del forn de vidre donà nom, per la continuïtat o per l'existència des d'antic, a l'anomenat carrer del Vidre. Aquest carrer, avui encara existent amb el mateix nom, fou mutilat per la construcció, a mitjan segle XIX, de l'actual plaça Reial.

La importància del forn queda palesa en el fet que sovint s'utilitzava el terme "forn de vidre" com a topònim per tal de situar illes de cases i habitatges ${ }^{19}$.

Del mateix vidrier Pere Barceló hi ha altres notícies. Així, per exemple, el 4 de febrer de l'any 1378, els consellers li van concedir carta de ciutadania $^{20}$. Un altre document diu que Pere era ja mort el 12 de març del 1385 i que el seu germà Miquel Barceló, vidrier de Barcelona, era el seu hereu universal ${ }^{21}$.

Un altre Barceló, de nom Bernat, s'encarregà posteriorment del forn. No queda clara la relació familiar exacta entre Bernat i els dos vidriers anteriors. Aquest vidrier portà el forn per poc temps, ja que l'any 1394 era mort. Francesca, la seva vídua i hereva de la meitat dels seus béns, rebia del rei Joan I el dia 8 d'agost d'aquell any, la concessió per poder cremar quatre somades de llenya petita a part de les quatre somades de llenya grossa que tenia acceptades des d'antic. El rei li atorgava també que, a part dels tres

\footnotetext{
${ }^{18} \mathrm{ACA}$, Cancelleria, reg. 919, "Gratiarum 45. Pere III", ff. 149 v. i 150 r. Esmentat també a ACA, Reial Patrimoni, Batllia, vol. 544, "Regiarum II" ff. 118 r. i v., entre altres textos de censos posteriors.

${ }^{19}$ Així passa, per exemple en un fogatge del 1374: "Ferrer, hostaler, prop lo forn del vidre". AHCB, Fogatges, XIX-1, f. $10 \mathrm{r}$.

${ }^{20} \mathrm{AHCB}$, Consellers, V-3, f. 20 r. Fou Albert Cubeles qui ens posà sobre el rastre d'aquest document.

${ }^{21}$ ACB, Notarial Capitular, Pere BorRell, 1385, f. s/n v.: 12-març-1385.
} 
obralls que ja hi tenia, pogués construir-ne un altre, de tal manera que en podia tenir fins a quatre. Per tot això hauria de pagar un cens anual de 12 diners, que s'havien de fer efectius per $\mathrm{Nadal}^{22}$. Estem parlant, doncs, d'un forn amb quatre obradors i amb un consum de combustible important. Tot això mostra el bon funcionament del negoci i la prosperitat de la producció del forn de vidre de Barcelona, que havia d'abastar un mercat ampli i que havia d'oferir diverses qualitats.

A Francesca la succeí, en la direcció del forn, Miquel Çabastida, de qui els documents no mostren per quant de temps es feu càrrec del forn de vidre de Barcelona ${ }^{23}$.

\subsection{El forn de Viladalls al segle $X V$}

Cal pensar que l'any 1436 es féu un nou canvi de titular del forn de vidre, amb l'abonament de 43 anys endarrerits del pagament dels censos al rei. No fou, en aquest cas, Miquel Çabastida qui abonà els cens, sinó que aquests anaren a càrrec de Ramon Lleonard Derç, barber, que es feia dir "senyor del forn de vidre de Barcelona". La forma d'esmentar la propietat i el fet que el propietari no sigui un vidrier, mostra que en aquest moment hi havia una clara separació entre la propietat del forn i aquells que hi treballaven.

Els pagaments anuals es feren durant aquests anys de forma continuada i els tenim perfectament documentats any rere any fins al $1459^{24}$.

Ramon Lleonard Derç pagà així durant uns anys el cens com a propietari del forn de vidre de Viladalls. En canvi, l'anotació del pagament del 15 de febrer de l'any 1453 explica que l'abonament el va fer Elionor, muller de Joan Bach, filla i hereva universal del difunt Ramon de Vilarrohir, especier, que tenia la concessió del forn de vidre de Barcelona "que era assats prop de Viladalls" 25 . Els documents no deixen dubtes sobre el fet de la identificació de totes aquestes referències amb el mateix forn en fer contínuament esment a les concessions fetes als seus propietaris en nom del rei Joan I l'any 1394.

Es fa necessari remarcar, però, que als pagaments dels censos del 1453 hi ha una referència que menciona la creació d'un altre forn. Es tracta

${ }^{22}$ ACA, Cancelleria, reg. 1908 "Gratiarum. Joan I", ff. 101-102. Esmentat també a ACA, Reial Patrimoni, Batllia, vol. 374 , f. 159 v., al vol. 415 , f. 41 v. i al vol. 327 , f. 1415 r.

${ }^{23}$ ACA, Reial Patrimoni, Batllia, vol. 327, f. 1415 r. i vol. 327, f. 481 r.

${ }^{24}$ ACA, Reial Patrimoni, Batllia, vol. 1121, f. 95 v.. vol. 415, f. 41 v., vol. 416, f. 24 r.; vol. 363, f.' 31 r.; vol. 417 , ff. 336 r. 337 r. vol. 357 , ff. 49 v.; vol. 1111,'f. 83 r.; vol. 1112 , f. 91 r.; vol. 1113 , f 75 v.; vol. 1114 , f. 80 v.; vol. 1115 , f.' 78 r.; vol.'1116, f.'67 r.; vol', vol. 1124 , f. 98 v.; vol. 1125 , f. 9 i'r.

${ }_{25}^{25}$ ACA Reial Patrimoni, Batllia, vol. 417, ff. 336 r - 337 r., vol. 420, f. 304 r. i vol. 410 , f. 173 r. L'honorable Ramon de Vilarrohir, especier, surt esmentat en diversos documents anteriors (1446-50) en relació a l'obligació que tenia de pagar uns censos per uns albergs barcelonins (ACA, Reial Patrimoni, Batllia, vol. 1118, f. 226 r. i vol. 1121 f. 181 r.). 
de l'establiment concedit a Bartomeu Llorenç d'un forn de vidre que se situaria al Pla d'en Llull i del qual parlarem més endavant ${ }^{26}$.

Cal aquí només esmentar les anotacions fetes en els manuals de la Batllia General de Catalunya segons les quals, l'any 1463, feia ja temps que no es realitzava el pagament del cens del forn de vidre de Viladalls per problemes de solvència del seu propietari Lleonard Derç. Es diu també que ell no tenia res amb què respondre ja que era molt pobre i que el forn s'havia "derrohit" i, que malgrat l'exclusiva que aquest tenia i davant la inexistència real de forn de vidre a Barcelona, s'havia donat llicència amb exclusivitat, a Bartomeu Llorenç i al seu forn de vidre del Pla d'en Llull, a Barcelona. El cens del forn de Viladalls quedà, per tant, en suspens. El mateix text es repeteix en alguns volums posteriors (1464-68) ${ }^{27}$. Cal fer notar la curiositat de l'explicació, ja que les dates s'encavalquen fins a tal punt que l'establiment del forn que es concedeix a Bartomeu Llorenç és anterior (1453) a l'aturada dels pagaments dels censos del forn de Viladalls (1459).

Les contradiccions segueixen més endavant.Malgrat la nova exclusivitat atorgada al forn del Pla d'en Llull, i en un fet que cal considerar com un intent de recuperar l'ús del forn, el 25 d'octubre del 1469, el conegut brodador barceloní Antoni Sadurní es féu càrrec d'abonar el cens i de pagar una suma que corresponia al total de setze anys de cens pels privilegis concedits al forn de vidre de Viladalls. I diu que ho fa en nom d'Elionor, ara ja vídua del mercader Joan Bach ${ }^{28}$.

En les anotacions dels censos rebuts l'any 1471 es deixava constància que no s'havia rebut el cens de l'esmentat forn ${ }^{29}$. En canvi, s'hi registren els pagaments corresponents als anys 1470 a $1474^{30}$.

Una anotació del 25 de desembre del 1477 fa dubtar sobre l'existència d'algun altre forn a la mateixa zona o sobre la duplicació en la possessió d'aquest, ja que l'anotació diu que es pagaven els censos de 38 anys, que corresponien al període 1440-1477, mentre l'últim pagament que havia fet efectiu Antoni Sadurní arribava ja al $1469^{31}$. En aquest pagament s'anota que qui havia fet l'abonament havia estat la mateixa Elionor que abans hem esmentat. En una anotació del 1484 es parla, però, d'un error en els albarans anteriors i es rectifica amb un retoc de diners; sembla referir-se precisament als fets que s'esmenten ${ }^{32}$.

I de nou, el 9 d'abril de l'any 1482, el brodador Antoni Sadurní pagà el cens corresponent a nou anys (1474-1482) per la concessió del forn de vidre de Barcelona que té (prop de Viladalls) Francina, muller de Joan Santander,

\footnotetext{
${ }^{26}$ ACA, Reial Patrimoni, Batllia, vol. 417, ff. 336 r.-337 r.

${ }^{27}$ ACA, Reial Patrimoni, Batllia, vol. 1128, f. 71 r.; vol. 1129, f. s/n; vol. 1130, f. 69 r.; vol. 1131 f. s/n; vol. 1132 , f. 62 r.

${ }^{28}$ ACA, Reial Patrimoni, Batllia, vol. 410, f. 112 r. i vol. 417, f. 337 r.

${ }^{29}$ ACA, Reial Patrimoni, Batllia, vol. 1134, f. s/n i vol. 1135, f. 74 r.

${ }^{30}$ ACA, Reial Patrimoni, Batllia, vol. 1136, f. 82 v., i vol. 1139, f. 129 r.

${ }^{31}$ ACA, Reial Patrimoni, Batllia, vol. 322, ff. 19 v.-20 r.

${ }^{32}$ ACA, Reial Patrimoni, Batllia, vol. 417, f. 337 r.
} 
coraler, ciutadà de Barcelona. Francina havia estat primer l'esposa del ja difunt Joan Derç, alies Lleonard, coraler, i era hereva dels béns que havien estat d'Elionor, muller de Joan Bach, mercader, i hereva també dels béns del seu pare, el difunt Ramon de Vilarrohir. S'hi explica, a més a més, que és el mateix forn del vidre que havia estat de Ramon Lleonard Derç, barber ${ }^{33}$.

L'any 1482, els dies 9 i 20 d'abril, el rei cobrà 1 lliura 4 sous d'Antoni Sadurní i 13 sous de Francina d'allò que li corresponia pel dret de senyoria per la donació que l'esmentada Francina, com a hereva dels béns del seu primer marit, feia a Antoni Sadurní, brodador de Barcelona, de la facultat de construir un forn de vidre segons les concessions fetes temps enrere a Pere Barceló. Francina, per la seva banda, cobrà 12 lliures d'Antoni Sadurni ${ }^{34}$.

Els anys següents es feren efectius els pagaments dels censos anuals corresponents: el 31 d'agost del 1484, dels anys 1482 i 1483; i el 23 de març del 1489 els de $1484-89^{35}$.

De totes formes, per les mateixes dates, Antoni Sadurní instal·là, amb el vidrier Jaume Granada, un forn de vidre a Montcada, del qual parlarem més endavant. En la petició del permís per a la construcció d'aquest forn, es comenta el fet de la impossibilitat de reprendre els treballs dins Barcelona, ja que no s'havia pogut refer el forn de Viladalls. Possiblement, l'intent de Sadurní de reiniciar l'activitat de l'antic forn degué enfrontar-se amb la instal-lació en exclusivitat del nou forn del Pla d'en Llull, dirigit per un vidrier i que potser comptava amb el suport municipal.

A partir d'aquí desapareixen les rebudes de cens del forn de Viladalls, tot i que hi ha algunes referències on es diu que aquest cens ja no es pagava, com l'anotada el 28 de març de $1565^{36}$. Altres textos del segle XVI parlen de nou dels censos que havien pagat temps enrere Miquel Çabastida primer, i Lleonard Derç, després, amb l'explicació que a mitjans de segle no se sabia qui n'era el propietari ni que ningú fes ús del privilegi concedit a aquest forn de vidre ${ }^{37}$. En un altre compte de 1586-87 s'explica també l'antic cens ${ }^{38}$.

\footnotetext{
${ }^{33}$ ACA, Reial Patrimoni, Batllia, vol. 417, ff. 336 r.-337 r.

${ }^{34}$ ACA, Reial Patrimoni, Batllia, vol. 417, f. 337 r.; i vol. 385, f. 69 r., vol. 327, f. 481 r., vol. 437 , vol. 382 , f. 380 r., vol. 359 , f. 4 r. i 420 , f. 304 r.

${ }^{35}$ ACA, Reial Patrimoni, Batllia, vol. 410, f. 173 r.

${ }^{36}$ ACA, Reial Patrimoni, Batllia, vol. 374, f. 83 r.

${ }^{37}$ ACA, Reial Patrimoni, Batllia, vols. 371, f. s/n v. i 373, f. 126 v.

${ }^{38}$ ACA, Reial Patrimoni, Batllia, vol. 1142, "Primer i darrer compte del noble don Joan Icart... any $1586-87$ ", f. $138 \mathrm{r}$.
} 


\section{ALTRES FORNS DELS SEGLES XIV I XV (1352-1505)}

Mentre a Barcelona funcionava el forn instal lat a la zona de Viladalls, a l'entorn de la ciutat i més enllà de la zona d'exclusivitat d'aquest forn, se n'instal-laven d'altres.

Hi ha notícies bibliogràfiques de l'existència de forns de vidre durant aquests segles a indrets tan diversos com Bell-lloc d'Aro (Baix Empordà), Rajadell (Bages) o al Rosselló: a les poblacions de Perpinyà, Palau del Vidre, La Roca d'Albera, Requesens i Sureda, entre d'altres. Les notícies del forn de vidre de Vallbona, també al Rosselló, ens parlen, entre els any 1419 i 1421 , d'un forn situat prop de l'abadia cistercenca del mateix nom i de la presència, com a mestres del forn, de vidriers provinents de Barcelona, com ara Jaume Roger o Joan Coloma ${ }^{39}$.

Relacionarem, a continuació, algunes notícies documentals que aporten informació directament relacionada amb forns de vidre de Barcelona i rodalia o amb vidriers de la ciutat que s'instal-laren en llocs més llunyans.

\subsection{Instal·lació d'un forn de vidre a Mallorca (1352)}

Un dels documents més antics sobre el tema no es refereix a l'entorn de Barcelona però està relacionat amb aquesta ciutat. El dia 6 de febrer del 1352, el rei Pere el Cerimoniós concedia a Miquel Bartomeu "de Barcelona" permís per construir a la "ciutat de l'Illa de Mallorca" un forn per fer obra en vidre. Miquel Bartomeu, qui treballava en l'execució de peces de vidre, podia fer i refer un forn, o manar que el fessin o el refessin, on ell volgués dins l'esmentada ciutat de Mallorca. En el dit forn es podria treballar o fer treballar tota obra de vidre. El document fa també un comentari sobre la llenya a l'Illa ${ }^{40}$.

\subsection{Instal·lació del forn de vidre de Badalona (1360)}

Una altra dada primerenca sobre forns de vidre que es pot aportar aquí a partir dels documents consultats sobre els establiments reial, es refereix a Badalona. El document és datat el dia 17 de març del 1360 i parla d'una carta reial del mes de juliol del 1347. En aquesta carta, el rei Pere el Cerimoniós autoritzava Francesc d'Aversone, ciutadà de Barcelona, a edificar i tenir en perpetuïtat un forn "ad decoquedum vitrum" dins la parròquia de Santa Maria de Badalona. En aquest forn, ell i els seus successors podien obrar o fer obrar qualsevol feina en vidre i tot allò referit al seu ofici. El cens, mentre ell o els seus explotessin el forn, seria d'un maravedís d'or l'any (que eren 10 sous),

\footnotetext{
${ }^{39}$ Per als forns de vidre del Rosselló vegeu M. CAMIADE i D. FONTAINE $o b$. cit.

${ }^{40}$ ACA, Cancelleria, reg. 1416, "Major 7. Pere III", ff. 155 r. i v. (f. 158 antiga numeració).
} 
a pagar per Nadal. A més a més, tenien la potestat d'arrendar o vendre la concessió. Pagaren 200 sous d'entrada ${ }^{41}$.

\subsection{Dades relaciones amb el forn de vidre de Sant Pere de Bigues (1407-1513)}

El dia 3 de gener de l'any 1407 consten unes al-legacions corresponents a la ciutadania del vidrier Francesc Ça Torra. En elles declaraven els seus veïns de Barcelona. D'aquestes declaracions es desprèn que coneixien l'esmentat vidrier i que aquest tenia dona i fills que vivien a Barcelona, al carrer de Vernet. Expliquen també que el vidrier tenia un forn de vidre a Bigues, prop de Granollers, d'on anava i venia contínuament, i que havien vist els seus missatgers amb bèsties carregades de vidre que anaven i venien de Bigues a Barcelona ${ }^{42}$.

$\mathrm{Al}$ mateix forn de Bigues es refereix la carta de ciutadania emesa pels consellers de Barcelona el dia 13 de març del 1423. En la declaració els veïns explicaven que el vidrier Pere Pujalt tenia casa amb alberg a Barcelona, a la parròquia de Sant Pere, al costat de l'abeurador. Que la casa no era d'ell sinó que la llogava a la dona Sança, vídua del teixidor de llana Pere Say. Que el vidrier tenia muller i fills, però que no vivien amb caràcter permanent a la ciutat, ja que tenien un forn de vidre a Bigues que els obligava a anar i venir, però que ells voldrien viure a la ciutat i que hi passaven les festes. Un matrimoni tenia cura de casa seva i s'encarregava també de rebre el vidre que Pere Pujalt els trametia. Deien que pagava, com a bon ciutadà que era, totes les càrregues que se li demanaven ${ }^{43}$.

Un altre vidrier que en dates posteriors se situa a Bigues és Francesc Granada. L'11 de setembre del 1505, aquest vidrier cedia en arrendament per un temps, al també vidrier Jaume Çavertés, un obrall del forn de Sant Pere de Bigues, amb les eines del forn, i li permetia l'ús de la botiga que hi tenia. També li havia de proporcionar la llenya que li calgués i els mossos necessaris per al seu funcionament. La producció es vendria a Barcelona a través del mercader Antoni Confós. Jaume Çavertés pagaria 67 lliures $^{44}$.

Uns anys després, el 10 de novembre del 1513, Joan Fugida, vidrier de Barcelona, reconeixia i prometia satisfer un deute que tenia amb Francesc Granada, vidrier de Sant Pere de Bigues ${ }^{45}$.

\footnotetext{
${ }^{41}$ ACA, Reial Patrimoni, Batllia, vol. 610, f. 1 r., esmentat també al vol. 359, f. 162 r., de la mateixa secció $\mathrm{i}$ sèrie.

${ }^{42}$ AHCB, Consellers C-V, 3 "Informacions de ciutadania 1375-1420": 3-gener-1407. Ens va assenyalar aquest document Albert Cubeles, a qui agraïm la informació donada. Altres notícies sobre el vidrier Francesc Ca Torra a AHPB, 93/11, Gabriel TERRASSA, Manual anys 1442-43: 11-agost-1442 i AHPB, 174/1, Francesc TERRASSA, Primer Manual, anys 1438-45: 2-maig-1444.

${ }^{43} \mathrm{AHCB}$, Consellers, C-V, 4, "Informacions de ciutadania 1415-29": 13-marc-1423. Fou Albert Cubeles qui ens assenyală la importància de la sèrie que aquí esmentem i que ha donat tres documents força interessants per a la nostra recerca.

${ }^{44}$ AHPB, 239/29, Pere TrITER, Manual de contractes núm. 29: 11-octubre-1505, f. s/n.

${ }^{45}$ AHPB, 222/14, Esteve SOLEY, 92 manual: 10-novembre-1513, ff. 142 v. -43 r.
} 


\subsection{El forn de vidre de Sant Vicenç de Vallromanes (1429-1484)}

Les referències al forn de vidre situat als afores de Barcelona, al terme de Sant Vicenç de Vallromanes, vénen donades a través d'uns documents referits a una família de vidriers, els Sala ${ }^{46}$.

Del 26 de maig del 1429, data el jurament que féu Andreu Baldoni, fill d'Eulàlia i del difunt Andreu Baldoni de ciutat de Mallorca, d'estar per tres anys amb Pau Sala, vidrier de Barcelona, per aprendre l'ofici de vidrier i servir-lo en allò lícit que li demanés. Pau Sala l'acceptà com a deixeble i prometé mantenir-lo, vestir-lo i calçar- lo $^{47}$. Acabat aquest període, el 26 d'agost del 1432, el mateix vidrier prengué un nou aprenent. En aquest cas fou Bernat Jonquers, vidrier obrador habitant de la parròquia de Sant Vicenç de Vallromanes de la diòcesi de Barcelona, qui prometé estar un any amb Pau Sala, vidrier de Barcelona, obrant vidre i servint-lo en allò que ell li demanés. Pau Sala l'acceptà i prometé pagar-li 27 lliures 10 sous i una quantitat en espècies $^{48}$.

En dos documents consecutius, datats el 15 de març del 1455, Francesc Clot i Pau Sala, vidriers de Barcelona, es reconeixien un deute mutu resultat del qual en restaven 7 lliures i 11 sous del salari que Pau Sala devia pels jornals del serf captiu Martí, propietat de Francesc Clot, que treballava al forn de vidre que Pau Sala tenia a Vallromanes ${ }^{49}$.

També relacionat amb la producció de vidre és un document de tres anys després, del 15 de juliol del 1458, en el qual el mateix Pau Sala i el seu fill Francesc Sala, vidriers de Barcelona i habitants de la parròquia de Sant Vicenç de Vallromanes, reconeixien a Bartomeu Fontanils, mercader de Barcelona, un deute de 123 lliures 13 sous i 7 diners pel preu dels 91 quintars de sosa que els calien per a llur ofici de vidriers ${ }^{50}$.

L'1 de novembre del 1464 trobem un altre text que ens relaciona els Sala amb els Granada segons el qual Miquel Granada i Pau Sala, els dos vidriers de Barcelona i el segon d'ells habitant de la parròquia de Sant Vicenç de Vallromanes, intervingueren en un arbitri ${ }^{51}$.

La relació de la família Sala amb altres nissagues de vidriers està documentada en les mateixes dates. Els trobem relacionats, tant amb els

\footnotetext{
${ }^{46} \mathrm{Ja}$ l'any 1408, el 20 de setembre, un vidrier de Barcelona de nom Antoni Sala va fer de testimoni en un document en el qual Raimon Roger, també vidrier de Barcelona, reconeixia un deute amb Joan Xatart, vidrier de Girona. AHPB, 63/1, Juan PEREYADA, "Manual 14", anys 1408-09, f. 7 v.

${ }^{47}$ AHPB, 113/26, Bernat PI "34 manual comú”, ff. s/n r. i v.: 26-maig-1429.

${ }^{48}$ AHPB, 113/36, Bernat PI, Manual anys 1432-33, ff. 49 r. i v.

${ }^{49}$ AHPB, 184/1 Antoni Martí BASTER, "Manuale 9 instrumentorum et contractuum", any 1455: 15-març-1455.

${ }^{50}$ AHPB, 208/2, Pere TARAFA, Manual 3, anys 1458-59: 15-juliol-1458.

${ }^{51}$ AHPB, 208/5, Pere TARAFA, Manual comú 11, anys 1464-65: 1-novembre-1464.
} 
Granada com amb els Llorenç, famílies que treballaren en el forn de vidre del Pla d'en Llull ${ }^{52}$.

En uns documents datats entre els anys 1473 i 1475 es parla de nou del forn de vidre de Sant Vicenç de Vallromanes en relació als pagaments d'uns deutes entre Francesc i Pau Sala i Francesc Çarovira, també vidrier ${ }^{53}$.

Francesc Sala era mort l'any $1492^{54}$. L'any 1498 , la seva vídua Antònia, en document del dia 9 d'agost del mateix any, arrendà la propietat (el mas, el forn de vidre i les pertinences que hi havia) que tenia en usdefruit en l'esmentada població i que havia heretat el seu fill Joan Sala. Es diu que la propietat rep el nom "del vidre"55.

\subsection{Els forns de vidre de Montcada (1486-89)}

Com hem esmentat en parlar del forn de vidre de Viladalls, a Barcelona, la solució que Antoni Sadurní trobà front la impossibilitat d'instal-lar i refer el forn de vidre dins Barcelona, fou la de construir-lo en uns terrenys situats dins el terme de Montcada. Així, el mencionat brodador presentà al Consell de Trenta-dos de la Ciutat de Barcelona una súplica, el dia 25 d'abril del 1486, entorn l'obertura d'un forn de vidre a la baronia de Montcada. La deliberació del Consell fou favorable ${ }^{56}$.

Antoni Sadurní engegà ràpidament la construcció del forn a Montcada. En els mesos següents s'abonaren diverses quantitats per les teules i l'obra en ferro per a l'obra del forn de vidre que es feia a la casa d'Ambrosi Vallmanya, al terme de Montcada. Segons la documentació que coneixem, en aquesta construcció, i possiblement en l'explotació posterior del forn, hi col·laborà el vidrier Jaume Granada ${ }^{57}$.

\footnotetext{
${ }^{52}$ La relació entre els vidriers Sala i els Granada està documentada des de l'any 1445, quan el mercader de vidre Jordi Sala i la seva esposa declaren un deute pel vidre adquirit a Francesc Granada. AHPB, 93/12, Gabriel TERRASSA, Manual 20, f. s/n: 18-desembre-1445. Pel que fa a la relació amb els vidriers Llorenç, sabem que Antònia, vídua del vidrier de Barcelona Joan Llorenc, era germana de Pau Sala vidrier de Sant Vicenç de Vallromanes. AHPB, 166/43, Honorat SACONAMINA, Manual 1466-67: 4-setembre-1466, f. s/n r. Vegeu Sílvia CANELLAS I Carme DoMínGUEZ, El forn de vidre del Pla d'en Llull de Barcelona (1447-1640) en els protocols notarials, "Estudis Historics i Documents dels Arxius de Protocols", núm. XXIII (2005), Col·legi de Notaris de Catalunya, Barcelona, pp.141-172; en concret les pp. 150 a 152 i 158.

${ }^{53}$ AHPB, 174/21, Francesc TERRASSA, 24 manual, anys 1472-73: 10-abril-1473. El deute es considera saldat, al peu del mateix document, amb data 27-gener-1475.

${ }^{54}$ AHPB, 249/7, Miquel ForTUNY, 7 manual, anys 1491-92: 7-febrer-1492. Es parla de la vídua Antònia i del seu cunyat Vicenç Sala, vidrier de Barcelona.

${ }^{55}$ AHPB, 221/9, Joan MATES, Manual anys 1498-99: 9-agost-1498. De l'any 1484 consten els capítols matrimonials entre Joan Sala, vidrier de Barcelona 1 fill de Vicenc Sala. AHPB, 237/1, Bartomeu SUMES, Manual de contractes 1484: 24-març-1484. Seguim trobant documents sobre la família Sala fins més enllà de mitjan segle XVI: 1'any 1565 , la vídua de Pere Sala i el vidrier Bartomeu Sala confessaven tenir vinyes, unes peces de terra i cases i no pagar censos al rei. ACA, Reial Patrimoni, Batllia, vol. 427, f. $137 \mathrm{r}$.

${ }^{56} \mathrm{AHCB}$, Consell de Cent, Registre de Deliberacions, II-28, anys 1485-87, ff. 34 v., 35 r. i 36 r. (anotació inicial) i ff. 39 r. 172 v. (resolució).

${ }^{57}$ En relació al forn del Pla d'en Llull, vegeu les informacions en l'apartat corresponent. Per al forn de Montcada i la relació entre Antoni Sadurní i Jaume Granada: AHPB, 222/8, Esteve SolEY, Manual any 1486: 18-VI i 1-VII i tres àpoques de 20-VIII-1486.
} 
No tenim notícia del futur que tingué aquest forn ni de la seva producció, però tres anys després, el Consell de Trenta-dos de la ciutat de Barcelona rebia una nova petició d'instal'lació d'un forn de vidre a la mateixa població per part, en aquesta ocasió, del vidrier Vicenç Sala i dels seus fills ${ }^{58}$. La deliberació tingué una conclusió favorable al vidrier. No se sap tampoc res més sobre el funcionament del forn, però del mateix Vicenç Sala hi ha algunes notícies posteriors ${ }^{59}$. Com la del 21 de juny del 1504, en la qual Vicenç Sala, vidrier de Barcelona, i els seus germans Joan i Pau intervenien en un document sobre la propietat del terme de Montcada que tenien cedida per Antònia, vídua del boter Joan Riera ${ }^{60}$.

La coincidència de noms fa plantejar-se, malgrat les diferències cronològiques, la possible relació familiar entre els qui varen dirigir el forn de Sant Vicenç de Vallromanes i aquest segon forn de Montcada.

\section{EL FORN DE VIDRE DEL PLA D’EN LLULL (1453-1640) ${ }^{61}$}

\subsection{Bartomeu Llorenç i el forn de vidre del Pla d'en Llull (1453-92)}

El vidrier Bartomeu Llorenç vivia l'any 1448 a Barcelona, a la mateixa illa de cases on es troba el monestir de Santa Anna ${ }^{62}$. Era fill del també vidrier Gispert Llorenç i de la seva esposa Justa, qui un cop mort Gispert es casà en segones núpcies amb Joan Alemany, porter del portal dels orbs de Barcelona ${ }^{63}$.

No tenim clara la relació entre aquesta família de vidriers i els que portaren el forn de vidre de Sant Vicenç de Vallromanes ni amb els qui s'establiren a Caldes de Montbui, però sabem que el 14 de setembre de l'any 1466, Antònia, vídua del vidrier de Barcelona Joan Llorenç, vengué al seu

${ }^{58} \mathrm{AHCB}$, Consell de Cent, Registre de Deliberacions, II-29, anys 1487-1489, ff. 97 r.-98 r.: 30-III-1489.

${ }^{59} \mathrm{El}$ mateix any 1489, Vicenç Sala, vidrier, intervenia en diversos documents. AHPB, 249/4, Miquel FORTUNY, 4 manual, anys 1488-89: 30-VI-1489 i 14-X-1489. L'any 1493 Vicenc Sala, vidrier de Barcelona, és esmentat a AHPB, 249/10, Miquel FORTUNY, Manual 10, anys 1493-94: 4-XII-1493 i a AHPB, 249/11, Miquel FORTUNY, 11 manual, any 1494: 31-V-1494. Sobre les propietats que la família Sala tenia a Caldes hi ha també diversos documents on s'esmenten també Miquel Farell, vidrier de Caldes, i Vicenc Sala, vidrier de Barcelona. AHPB, 249/2, Miquel FORTUNY, Manual anys 1487-88: 3-juliol-1487.

${ }^{60}$ AHPB, 213/1, Joan FANER, 54 manual, any 1504: 21-VI-1504.

${ }^{61}$ Vegeu S. CAÑELlas i C. DOMÍNGUEZ, ob. cit.

${ }^{62} \mathrm{AHCB}$, Consell de Cent, Fogatges, XIX-7: 1448.

${ }^{63}$ AHPB, 159/24, Bernat MONTSERRAT, 37è manual, anys 1453-54: 14-III-1454. 
germà Pau Sala, vidrier de Sant Vicenç de Vallromanes, les possessions que ella tenia al carrer del Pont de Caldes de Montbui ${ }^{64}$.

Coneixem, en canvi, l'establiment en emfiteusi perpètua, que el conseller de la Batllia General de Catalunya, per potestat del rei, concedia al vidrier Bartomeu Llorenç el 2 de gener del 1453. El vidrier rebia llicència per fer un forn on poder obrar i fer obrar recipients de vidre. La localització, dins la ciutat de Barcelona, la triaria el mateix Llorenç. El cens que s'hauria de pagar seria d'un maravedís d'or, és a dir 9 sous, cada any i el pagament s'havia de fer efectiu per la festivitat de Pasqua de Resurrecció. Per censos i textos posteriors sabem que el forn se situà des d'un inici entre el carrer de Cavaroques i el de Pere de Vic, tocant el Rec Comtal, a la zona del Pla d'en Llull. S'establia que el forn es podia modificar com i quan es volgués, i reconstruir-lo o fer-lo de nou; també es decidia que no es donaria cap més llicència per a la construcció de cap altre forn de vidre dins la ciutat de Barcelona ni en dues llegües a l'entorn.

Aquest establiment es posava en contradicció, com hem vist més amunt, amb el forn de Viladalls, atorgat temps enrere a Pere Barceló. Segons alguns documents aquest antic forn havia caigut pel desús i el seu propietari, el barber Lleonard Derç, no pagava els censos reials, ja que era considerat insolvent ${ }^{65}$.

Podria ser l'experiència del que va succeir amb l'antic forn, probablement mig abandonat en aquell temps, el que va aconsellar la Batllia perquè Bartomeu Llorenç, propietari del nou forn, es comprometés a tenir-lo en bones condicions i en funcionament per tal d'elaborar-hi recipients de vidre, i que la seva activitat no pogués aturar-se més de dos mesos. L'entrada que es pagà fou de 3 florins d'or d'Aragó ${ }^{66}$. Els 33 sous corresponents de l'esmentada entrada es van fer efectius el dia 9 de març del $1454^{67}$.

Possiblement en relació a la instal-lació d'aquest forn i a la seva posada en marxa, el dia 14 de març de l'any 1454, Bartomeu Llorenç reconeixia (juntament amb la seva mare) un deute de 43 lliures i 8 sous a Rafel Oller, mercader de Barcelona, que eren part de les 87 lliures i 8 sous

${ }^{64}$ AHPB, 166/43, Honorat SACONAMINA, Manual 1466-67: 14-setembre-1466. Del mateix Joan Llorenç sabem que l'any 1443 nomenà procurador seu a Jordi Pometa, espaser de Barcelona, per tal que procurés cobrar d'uns deutors seus de València. AHPB, 174/1, Francesc TERRASSA, Primer Manual, anys 1438-45: 11-XI-1443. L'any 1450 el mateix Llorenc intervingué en un altre document. AHPB, 134/50, Guillem JoRDÄ major, Manual 14, anys 1449-50: 2-VII-1450. Anys més tard, el 1496, se signaven els capítols matrimonials d'un altre vidrier del mateix cognom, Gabriel Llorenç. ÀHPB, 213/5, Joan FANER, Manual anys 1496-97: 1-maig-1496.

${ }^{65}$ ACA, Reial Patrimoni, Batllia, vol. 1135, "Llibre 2n ordinari de la 2a regència de Joan d'Argentona" 1471, f. 74 r.

${ }^{66} \mathrm{El}$ document de referència es troba a l'ACA, Reial Patrimoni, Batllia, vol. 71, "Llibre d'establiments 1", ff. 163 r. i v.-164 r. Hi ha resums d'aquest al vols. 72, f. 162 r. i al'vol. 144 ff. 42 r.-43 r.; és esmentat també en molts altres textos: vols. 117 f. 104 r. 418 , f. 56 r., 437, 327, f. 1415 r., 662, ff. 61 r. i v. i ACA, Reial Patrimoni, Establiments $i$ Precaris, Caixa 4, f'. $649 \mathrm{r}$.

${ }^{67}$ ACA Reial Patrimoni, Batllia, vol. 1124, "Llibre 8è ordinari de rebudes i dades de Jaume Janer" 1454 , f. $165 \mathrm{v}$. 
que havien costat 144 quintars de sosa que li calgueren per al seu ofici. Prometia retornar el deute abans del següent mes d'agost ${ }^{68}$.

El pagament dels censos (9 sous per any) corresponents al forn de vidre que es trobava al Pla d'en Llull de Barcelona, sota la capella de Santa Marta, i que s'havien de fer efectius anualment per Pasqua, foren realitzats de forma irregular: el 15 de maig del 1456 es pagaren els que es devien de 1454, 1455 i 1456; el 15 de gener del 1462 els dels anys 1456, 1457, 1458, $1459,1460,1461^{69}$.

El 23 de setembre de l'any 1461, Esteve Granada, de Granollers, acordava fer l'aprenentatge de vidrier amb Bartomeu Llorenç, a qui es comprometia a servir durant dos anys en tot allò lícit que li demanés. Bartomeu Llorenç es comprometia, a canvi, a ensenyar-li, durant aquest temps, l'ofici de vidrier i a pagar-li 13 lliures i 4 sous pels vestits i calçat que calguessin al deixeble ${ }^{70}$.

Entretant, hi va haver alguns problemes amb el forn. L'adveniment de la guerra civil, que afectà ràpidament les finances, tingué probablement repercussions en el negoci del vidre. Així, el 29 de febrer de l'any 1464, Ramon Carvero i el vidrier Bartomeu Llorenç presentaren dues suplicacions relatives a l'impost de la llenya. El vidrier Bartomeu Llorenç demanà l'exoneració d'aquesta taxa per poder tornar a obrir el seu forn de vidre. Un més després, el 23 de març, el Consell de Trenta-dos de la Ciutat de Barcelona donava resolució favorable ${ }^{71}$.

I dos mesos després, el 15 de maig, es pagaven de nou els censos endarrerits per al forn, corresponents als anys 1462, 1463 i $1464^{72}$. Malgrat els problemes que s'estaven produint a Catalunya, el cens anual es féu efectiu regularment els anys següents, entre el $1465 \mathrm{i}$ el $1468^{73} \mathrm{i}$ també els dels anys 1469 i $1471-74^{74}$.

Una nova incidència sorgí per al forn l'any 1473 en forma d'una probable competència en la producció. Així, el dia 3 de febrer es concedí permís al mercader de Barcelona Ponç Julià, procedent de Girona, per tal d'establir un nou forn, en aquest cas per recoure vidre. En el forn es produirien fils i cadenes de vidre $\mathrm{i}$ altres objectes de vidre que no fossin

\footnotetext{
${ }^{68}$ AHPB, 159/24, Bernat MONTSERRAT, 37è manual, anys 1453-54: 14-març-1454.

${ }^{69} \mathrm{ACA}$, Reial Patrimoni, Batllia, vol. 418, "Llibre segon d'Albarans", f. 56 r. i vol. 1127, f. $76 \mathrm{r}$.

${ }^{70}$ AHPB, 204/3, Jaume BARÚs, Manual 6: 23-XI-1461.

${ }^{71} \mathrm{AHCB}$, Consell de Cent, Registre de deliberacions, II-16, anys 1463-65, f. 104 r.: 29-II1464; full solt $r$. i v.: 23-III-1465; i ff. 108 v.-109 r.: 23-III-1464.

${ }^{72}$ ACA, Reial Patrimoni, Batllia, vol. 418, f. 56 r., i també vol. 1127, f. 83 r.

${ }^{73}$ ACA, Reial Patrimoni, Batllia, vol. 1127, f. 83 r., vol. 1128, 72 v., vol. 1129, s/n r. vol. 1130 , f. 69 v., vol. 1131 , f. s/n, vol. 1132 , f. 62 v.

${ }^{74}$ ACA, Reial Patrimoni, Batllia, vol. 1133 , f. s/n, vol. 1134 , f. s/n, vol. 1135, f. 90 r., vol. 1136, f. 100 r., vol. 1137 , f. 24 r., vol. 1138 , f. 90 r.; vol. 1139 , f. 145 v.
} 
recipients. Les institucions reials cobraren 9 sous per l'entrada i establiren un cens anual d'un sou' ${ }^{75}$.

La reacció de Bartomeu Llorenç fou ràpida i vint dies després renovava i ampliava, o especificava més clarament, la concessió que li havia fet el rei, per la qual cosa, el dia 23 de març del 1473, pagà 55 sous d'entrada ${ }^{76}$.

Efectivament, un dia abans, els representants de la Batllia General de Catalunya reconeixien per l'autoritat que el rei els atorgava, l'establiment previ concedit a Bartomeu Llorenç (1-febrer-1453) i recollien la demanda que aquest feia. El document diu que el forn de vidre havia treballat durant vint anys sense problemes i que s'hi produïen recipients de vidre i també altres objectes de vidre. També diu que en moments difícils per la guerra s'hi havia treballat subsistint gràcies a la producció alternativa de diversos objectes de vidre. La demanda es concretava en l'ampliació de l'exclusivitat a tota mena de feines en vidre dins Barcelona i dues llengües entorn de la ciutat. La petició s'acceptà i s'establí, en cas de ser contravinguda l'ordre, una pena de 200 florins a dividir en tres, una part pel qui feia la denúncia, una part pel forn de vidre legal i l'altra per a la Cúria Reial, i es donava ordre de l'immediat enderrocament del forn construït o en construcció il·legal. Es reconeixia al vidrier permís per gastar la llenya que li calgués sense cap mena de límits. Podia construir tants obralls com volgués i refer o modificar el forn, o fer-lo de nou, sempre que volgués. S'ampliava també el temps de possible inactivitat del forn, que passava de dos mesos a un any. En el document s'insisteix que el problema se centrava en els temps de guerra o de carestia de fusta, que havien ja portat veritables problemes de funcionament al forn i que dificultaven, i fins i tot feien impossible, la seva activitat. Tot i així, si es produïa una inactivitat superior a un any es perdria el privilegi concedit. A part dels 9 sous de la primera concessió es pagarien, ara, 3 sous més cada any per Pasqua ${ }^{77}$.

Així, el reconeixement de l'exclusivitat en totes les feines en vidre per al forn del Pla d'en Llull, xocà amb la construcció de l'obrador de Ponç Julià i féu obrir el procés pel qual Bartomeu Llorenç, vidrier, exposava que ell tenia una concessió de producció de vidre que prohibia la instal·lació d'altres construccions d'aquesta mena dins la ciutat de Barcelona ni a dues llegües entorn, i que la llicència concedida a Ponç Julià vulnerava aquest establiment. Ponç Julià exposà que la concessió de Llorenç es referia només a recipients de vidre i que ell no en feia. Llorenç respongué que la seva concessió afectava tota mena d'obra en vidre, ja que ell podia fer recipients però també altres

\footnotetext{
${ }^{75}$ ACA Reial Patrimoni. Batllia, vol. 668, "Manual 3 de Matheu Çafont, anys 1465-74”, ff. 88-89 i full solt a la coberta; i vol. 1136, "Compte segon de Joan Çarriera", f. 128 r.

${ }^{76}$ ACA, Reial Patrimoni, Batllia, vol.1136, “Compte 2n de Joan Çarriera” 1471-74, f.127 v.

${ }^{77}$ ACA, Reial Patrimoni, Batllia, vol. 72, "Llibre d'Establiments 2", ff. 162 r.-164 v.; esmentat també al vol. 144, ff. 42 r.-43, vol. 327 , f. 1415 r., vol. 359, f. 4 r. i vol. 1136 , f, $127 \mathrm{v}$.
} 
objectes. Finalment, el 18 d'agost del 1473 es declarà nul l'establiment fet a Ponç Julià i se li imposà "silenci" 78 .

Per tal que no es tornessin a produir fets similars, Bartomeu Llorenç va demanar a les institucions reials que es fes públic el seu privilegi. Joan d'Argentona que regia la Batllia General de Catalunya i, que en conseqüència estava acreditat pel rei per acomplir la demanda feta pel vidrier, ordenava fer públic l'establiment del forn de vidre atorgat al vidrier Bartomeu Llorenç, ciutadà de Barcelona. La crida la feu pública, amb dues trompetes, pels carrers de Barcelona, Franci Luna, corredor reial, el dia 2 de setembre del 1473. S'hi anunciava, així, la renovació de l'establiment i la condició que en l'esmentat forn Bartomeu Llorenç podia obrar o fer obrar no només recipients de vidre, sinó també fils de vidre i altres peces de vidre de qualsevol mena, i que tot gaudia del privilegi d'exclusivitat, de tal forma que ningú, que no tingués llicència del rei i permís exprés de Bartomeu Llorenç, no podia tenir cap altre forn ni forneret per fer o treballar vidre de cap mena dins la ciutat de Barcelona ni en dues llengües a l'entorn d'aquesta. En cas de contravenir això, l'infractor pagaria 200 florins d'or i se li enderrocaria el forn il·legalment construit ${ }^{79}$.

La renovació de l'establiment, del 8 d'octubre del 1477, repeteix les mateixes condicions fixades anteriorment ${ }^{80}$. Tot seguit s'anota el pagament del cens corresponent als any $1477-78^{81}$. L'any següent, el 23 de març del 1478 , es reconegueren i tornaren a confirmar els beneficis concedits a Bartomeu Llorenç $\mathrm{i}$ al forn de vidre de Barcelona del Pla d'en Llull ${ }^{82}$.

Uns anys després, el 24 d'octubre del 1484, en els moments del redreç promogut pel rei Ferran II i del sanejament de les arques públiques, el Consell de Trenta-dos demanà que fos deliberat pel Consell de Cent el cas de l'exempció de l'impost de la llenya de què gaudia el forn de vidre de la ciutat i del qual hem parlat més amunt ${ }^{83}$.

En els resums dels cobraments que rebia el nou rei, apareixen diverses referències al pagament del cens anual que feia Bartomeu Llorenç pel forn de vidre. Així, el 5 de març de l'any 1488, es recorden els privilegis concedits: l'exclusivitat en la producció de vidre, la prohibició de fer altres forns de vidre dins la ciutat de Barcelona i la situació exacta del forn de vidre,

${ }^{78}$ ACA, Reial Patrimoni, Batllia, vol. 1380, “Diversarum Rerum 52”, f. 46 r. També en parla el vol. 359 , f. 4 r i el vol. 1139 de la mateixa secció i sèrie, en el "3r libre de Rebudes de Joan Sarriera, de 1474 ", f. 153 r.

${ }^{79}$ ACA, Reial Patrimoni, Batllia, vol. 969, ff. 63 r. i 116 r.

${ }^{80}$ ACA, Reial Patrimoni, Batllia, vol. 71, "Llibre d'establiments 1 " ff. 163 r.-164. És esmentat també al vol. 144, ff. 42 r. -43 i vol. 327 , f. 1415 r., vol. 365, ff. 68 v. i 69 r. i a ACA, Reial Patrimoni, Establiments i Precaris, Caixa 4, f. 649 r.

${ }^{81}$ ACA, Reial Patrimoni, Batllia, vol. 1140 "Llibre 6 de Joan d'Argentona, any 1477", f. 80 r., i vol. 1141, "Llibre 7 de Joan d'Argentona, any 1478", f. 76 r. No hem localitzat els volums corresponents als anys 1475 i 1476 tot i que cal suposar que el cens es pagà regularment ja que no hi ha cap anotació que indiqui res en contra.

${ }^{82}$ ACA, Reial Patrimoni, Batllia, vol. 144, "Capbreu nou” 1437-1544, ff. 42 r.-43. Fet esmentat també al vol. 437, f. 4 v. i al vol. 547, ff. 173 r.-175 v.

${ }^{83} \mathrm{AHCB}$, Consell de Cent, Registre de deliberacions, II-27 (1483-85), ff. 93 v. i 103. 
construït entre els carrers de Cavaroques i de Pere de Vich, a la zona del Pla d'en Llull. Es recorda també que el forn no s'ha d'aturar més de dos mesos seguits i es fa referència als documents inicials de l'establiment ${ }^{84}$.

Bartomeu Llorenç fou un ciutadà significat de Barcelona i membre destacat del gremi de vidriers i esparters, la qual cosa devia reportar-li certs privilegis. Les ordinacions de la confraria d'esparters i vidriers de Sant Bernardí de l'any 1470, deien: "Ordonaren més avant los dits consellers e promens que attès que los mestres vedriers del forn de Barchinona portaren e porten lo càrrech de la dita confraria més que los altres, per la dita rehó en tot cas quiscun any un dels dits mestres vedriers dels forns de Barchinona haie ésser un dels promens de la dita confraria" ${ }^{85}$. Això els conferia una representació més directa davant del Consell de Cent.

La seva relació amb el món artístic i cultural del moment també degué ser important, com ho demostra el fet que el trobem esmentat en diferents documents en els quals hi figuren també noms com Antoni Sadurní, Jaume Vergós o Jaume Huguet ${ }^{86}$.

\subsection{El vidrier Mateu Llorenç. El tombant del segle XV al XVI}

Tot i que en les anotacions dels censos de l'any 1495 apareix encara, per darrer cop, el nom de Bartomeu Llorenç com a pagador, sembla que, per aquestes dates, va deixar la feina a la generació següent ${ }^{87}$. Així, el 4 de novembre de l'any 1493, el rei Ferran II concedia a Mateu Llorenç, vidrier i fill de Bartomeu, el dret de construcció d'un forn de vidre, per la qual cosa es diu que pagarà un sou l'any. La coincidència en el pagament i el fet que és a partir d'aquest moment que no trobem els pagaments de l'antic forn de Viladalls, ens fa pensar en la possibilitat que les dues concessions acabessin en les mateixes mans ${ }^{88}$.

Se sap, per la renovació que el rei va fer a Mateu Llorenç, que el pare del vidrier, era mort a finals de segle. D'aquesta manera l'empresa familiar passaria definitivament a mans del fill. Aquest darrer vivia, segons el fogatge del 1497, en l'illa de cases on era el forn de vidre ${ }^{89}$. És interessant el text de confirmació sobre l'ampliació concedida a aquest vidrier, datada el 5 de juny del 1497, ja que es fa un repàs de tots els privilegis, establiments i exclusives

\footnotetext{
${ }^{84}$ ACA, Reial Patrimoni, Batllia, vol. 144, ff. 42 r. - 43 r., també esmentat als vol. 327, f. 481 r. i a ACA, Reial Patrimoni, Establiments i Precaris, Caixa 4, f. 649.

${ }^{85} \mathrm{AHCB}$, Consell de Cent, Registre d'Ordinacions, IV-9 (1463-71), f. 173 v.

${ }^{86} \mathrm{La}$ relació entre Bartomeu Llorenc i el brodador Antoni Sadurní, es veu en alguns documents: el 18 de setembre de l'any 1486, amb el mateix brodador i amb Jaume Vergós i el vidrier Nicolau Xandres a AHPB, 222/8, Esteve SOLEY, Manual any 1486: 18-setembre-1486. Amb Jaume Huguet a AHPB 222/8, Esteve SOLEY, Manual any 1486, f. s/n (darrer document). Ens posà sobre el rastre d'aquest darrer document el doctor Francesc Ruiz.

${ }^{87}$ ACA, Reial Patrimoni, Batllia, vol. 420, ff. 170 r. i 517 r. i vol. 327, f. 481 r.

${ }^{88}$ ACA, Reial Patrimoni, Batllia, vol. 420, f. 517 r.

${ }^{89}$ Josep IGLESIAS, El Fogatge de 1497. Estudi i transcripció, Barcelona, Fundació Salvador Vives i Casajuana, 1991, p. $15 \%$.
} 
concedits anteriorment, que són explicats i repetits un a un: els 9 sous de cens deguts a l'establiment i exclusivitat inicial de 1453, els 3 sous de l'ampliació del 1473, on s'explica clarament que és en temps de guerra o de carestia de llenya que el forn té potestat per estar inactiu fins a un any seguit. Es parla també de la confessió del 1478 i, finalment, s'afegeixen també dos nous elements: l'ampliació del territori de treball i la producció de vidres esmaltats ${ }^{90}$.

Efectivament, el permís per tenir forn de vidre en producció s'estén a tot Catalunya i es permet a Mateu Llorenç mudar i variar, com i quan vulgui, el forn. L'exclusivitat és efectiva només, com en temps anteriors, dins la ciutat de Barcelona i en dues llengües a l'entorn, però ell i els seus successors o qui vulguin per a ells, podran treballar, amb permís reial, per totes les terres catalanes. El cens anual serà a partir d'aquest moment de 12 sous.

Sobre la producció de vidres esmaltats cal notar, per una banda, la referència a aquests entre la producció del forn, que fa pensar en les peces de vidres catalans que encara es conserven en diferents col-leccions i museus, $\mathrm{i}$ que a través d'aquest text caldria reivindicar com a procedents del forn (o dels forns) dels Llorenç, si no clarament del forn de vidre del Pla d'en Llull. D'altra banda, cal destacar també el fet que el pagament que es va fer a la Batllia en aquell moment no és en metàl-lic, com en els casos anteriors, sinó amb un bon exemple de la producció barcelonina de l'època: es parla d'una gran copa de vidre esmaltada, coberta amb tapa i meravellosament treballa$\mathrm{da}^{91}$.

L'any 1497, per ordre reial donada pel regent de la Batllia General de Catalunya, es feia públic l'establiment fet a Mateu Llorenç, vidrier i fill de Bartomeu Llorenç, també vidrier i habitant de Barcelona, en relació al forn de vidre de la ciutat de Barcelona. S'explicava que el privilegi concedit era de data 4 de novembre del 1493 i que en ell es renovaven uns d'anteriors concedits a Bartomeu Llorenç, pare de Mateu, per Jaume Gener el primer, i el segon per Joan de Argentona, els dos difunts i antics regents de la Batllia General de Catalunya. S'anunciava que Mateu Llorenç, i després d'ell els seus hereus o successors, posseirien a perpetuïtat un forn de vidre on ell i els seus podrien obrar i fer obrar qualsevol mena de recipients, fils o altra cosa de vidre. S'explicava que en tenien l'exclusivitat dins la ciutat de Barcelona i en dues llegües a l'entorn i que qui fes un forn sense permís exprés del rei i de Mateu Llorenç o el corresponent successor, hauria de pagar una multa de 200 florins d'or d'Aragó i li seria enderrocat el forn o forneret. En aquest cas s'afegia, a les estipulacions ja fetes al seu pare, la possibilitat de construcció d'un nou forn amb les mateixes condicions que l'anterior, tant si es volia fer dins Barcelona o en qualsevol altre indret de Catalunya, i en l'exclusivitat del

\footnotetext{
${ }^{90}$ ACA, Reial Patrimoni, Batllia, vol. 547, "Regiarum V", ff. 173 r.-175 v.

${ }^{91}$ "Unam cupam vitri smaltati magnam cohopertam et miriffice laborata". ACA, Reial Patrimoni, Batllia, vol. 547, f. 174 v.
} 
treball d'aquest material en la zona on ell s'instal·lés. També podia fer els canvis que li semblessin oportuns de localització o instal·lacions dels forns. Es parlava també, a diferència dels textos del seu pare, de l'elaboració i aplicació d'esmalts sobre vidre. Tot això es feia públic per tal que ningú en pogués al-legar desconeixement. L'encarregat de divulgar per la ciutat el privilegi renovat i les noves condicions fou, també en aquest cas, el trompeta i corredor reial Franci Luna. Aquest fet que succeïa el dia 26 de juny del $1497^{92}$.

Els 12 sous corresponents als censos dels anys 1495-1501 van ser abonats anualment per Mateu Llorenç, per Pasqua (29-IV-1496, 13-IV-1497, 5-VI-1497, 30-IV-1498, 5-IV-1499, 7-V-1500, 19-V-1501). Posteriorment, hi ha un salt fins al dia 24 d'abril del 1505 . Després, desapareix el nom d'aquest mestre dels documents referits al forn de vidre ${ }^{93}$.

Altres documents mostren que la producció del forn de vidre del Pla d'en Llull no es limitava a recipients ni objectes amb volum sinó que també feren vidre pla apte per a la realització de vidrieres. Tot i que en algun cas sabem que aquest procedia d'alguns dels forns situats entorn la ciutat, tal i com passà a principis de segle, concretament el 9 de juny del 1405, amb la compra a Joan Lorena, mestre del forn de vidre de Sentmenat, de mig quintar de vidre pla blanc per a la vidriera de Sant Antoni que Nicolau de Maraya estava fent per a la Seu de Barcelona. Tenim constància de la utilització del vidre pla procedent del forn del Pla d'en Llull per a la realització d'algunes de les vidrieres que es realitzaren a Barcelona. Així, el 18 d'abril del 1494, Mateu Llorenç, vidrier, cobrà pel vidre pla que havia venut per a les vidrieres de l'església de Santa Maria del Mar de Barcelona ${ }^{94}$. De dos anys després és una altra referència escrita d'aquests fets; el dia 1 de juliol del 1496 els cònsols de la Casa Llotja de Mar de Barcelona, anoten el pagament de 21 lliures barcelonines fet al vidrier Mateu Llorenç pels 3 quintars de vidre que ha venut per a la vidriera que Gil Fontanet feia per a l'esmentada Llotja ${ }^{95}$.

\subsection{L'arrendament de principis del segle XVI}

L'any 1506, i fins al 1510 és Francesc Trauer, mercader, qui fa el pagament dels 12 sous del cens pel forn de vidre del Pla d'en Llull ${ }^{96}$.

Com en èpoques anteriors, el fet que Francesc Trauer no fos vidrier no impedia que fos el propietari del forn, però no li devia permetre treballarhi directament. Degué, per tant, buscar-se treballadors i decidí fer l'explotació

\footnotetext{
${ }^{92}$ ACA, Reial Patrimoni, Batllia, vol. 969, f. 116 r.

${ }^{93}$ ACA, Reial Patrimoni, Batllia, vol. 420, f. 170 r.

${ }^{94} \mathrm{ACB}$, Llibre de l'Obra, 1405-07, f. 49 r.; AHPB, 222/9, Esteve SOLEY, 52 manual comú, any 1494 , f. $47 \mathrm{v}$.

95.AHBC, Llibres de la Junta de Comerç, núm. 149, "Albarans del dret del pariatge 14931496": 1-VIIl-1496.

${ }^{96}$ ACA, Reial Patrimoni, Batllia, vol. 420, f. 170 r.
} 
a través d'un contracte d'arrendament. Així, el dia 1 de maig del 1510, signà l'esmentat contracte segons el qual arrendava dos obralls del forn de vidre situat al Pla d'en Llull de la ciutat de Barcelona; l'arrendament en usdefruit es feia als vidriers Damià Granada i Joan Cornet ${ }^{97}$.

Amb el forn arrendaven també les eines grosses del forn, a més de proporcionar-los foc (la llenya necessària) i treballadors. Ells, per la seva banda, havien de fer la copa del forn i pagar 8 lliures i 10 sous cada any i ferse amb la pedra que els calgués per al funcionament del forn. A més, només podrien tenir dos morters grans i un d'auxiliar petit i no podrien llogar ningú que anés a altres forns a negociar si el propietari-arrendador no ho acceptava. Els arrendataris buscarien la gent que els calgués per al forn i el propietari n'abonaria els salaris. Aquest últim havia de fer el calcinador per als esmalts, tot i que els arrendataris l'haurien de demanar, quan els calgués, amb sis dies d'anticipació. S'establia també la quantitat de productes semielaborats i de vidre vell que havien d'aconseguir els arrendataris i com havia de ser la relació amb la clientela.

\subsection{El segle XVI i següents}

El 28 de març del 1516 i el 5 de febrer del 1517, el pagament dels censos al rei per aquest forn de vidre i les seves concessions i privilegis seguia a càrrec del mercader Francesc Trauer. Va ser ell qui pagà el cens dels anys 1515, 1516 i 1517, a 13 sous l'any, els 12 d'altres ocasions, més 1 de més per la nova confirmació ${ }^{98}$.

En canvi, el 3 de novembre del 1535 apareix un document que parla d'una rebuda de lluïsme datada el 16 d'abril del 1537 per la venda de la concessió sobre el forn de vidre del Pla d'en Llull feta per Elisabet, muller del ciutadà de Ciutadella (Mallorca) Feliu Pons al vidrier Bartomeu Arbonès o Narbonès ${ }^{99}$. Aquí s'explica que el forn, que té quatre obralls, es troba situat en unes cases amb quatre portals al carrer de Pere de Vich, sobre el Rec Comtal. El cens fixat era de 13 sous l'any, que s'havien de fer efectius per la festa de Pasqua.

Els pagaments dels anys següents $(1553-57,1561,1568,1576)$ van ser així realitzats per Bartomeu Arbones o Narbonès i la quantitat abonada, per Pasqua, era de 13 sous anuals ${ }^{100}$.

La incidència del forn en el seu entorn devia ser prou important ja que en diverses ocasions es fa referència a ell per tal de situar altres llocs que són

\footnotetext{
${ }^{97}$ AHCB, Fons Notarial, Sèrie XII, núm. 27, f. s/n: 1-maig-1510. Vegeu S. CAÑELlaS i C. DOMÍNGUEZ, $o b$. cit., p. 164-169.

${ }^{98} \mathrm{ACA}$, Reial Patrimoni, Batllia, vol. 421, f. 3 v.

${ }^{99}$ ACA, Reial Patrimoni, Batllia, vol. 387, f. 26 r. Apareix també al vol. 327, f. 1415 r.

${ }^{100} \mathrm{ACA}$, Reial Patrimoni, Batllia, vol. 370 , f. 13 r.; vol. 331 , f. 2 v.; vol. 332 , f. 2 v.; vol. 333 , f. 1 v.; vol. 334 , f. 1 v.; vol. 338 , f. 4 v.; vol. 370 , f. 13 r.; vol. 371 , f. 9 v.; vol. 373 , f 40 v.; vol. 376 , f. s/n.
} 
objecte de pagament de censos al rei. Així, ja a finals del segle XV, s'utilitzà com a punt de referència en una numeració dels focs al resum del padró de la ciutat de Barcelona de l'any 1496. Hi apareix una illa, situada entre el mar i el convent de Santa Clara, anomenada "lo forn de vidre", que correspon al Pla d'en Llull ${ }^{101}$. En el Padró de milícies de l'any 1516, es parla del carrer del Vidre, on no hi apareix cap vidrier, i del carrer del Forn del vidre, on surt esmentat un venedor de vidre de nom Joan Roig ${ }^{102}$. Se sap, també, que durant els anys 60 del segle XVI, es pagaven 6 diners de cens anual per l'ús d'un carreró tancat que estava prop del forn de vidre ${ }^{103}$.

En el cens del 1566 surt esmentat Magí Pellicer, qui serà el responsable dels pagaments més endavant, a partir del 1591, tot i que entre els anys 1567 i 1571 és encara Bartomeu Narbonès qui fa els pagaments i també qui apareix com a responsable de l'esmentat cens dels anys 1586-87 $7^{104}$.

Com dèiem abans, entre els anys 1591 i 1598, fou Magí Pellicer el responsable del forn de vidre del Pla d'en Llull de Barcelona, mentre que a principis del segle següent, la possessió del forn de vidre era de la família Brunes $^{105}$.

En efecte, en una anotació del 4 de juny del 1646 es parla de dues confessions fetes, els anys 1603 i 1618, a instàncies reials, sobre la possessió de l'esmentat forn, que, es diu, era de Joan Brunes, habitant de Caldes i dedicat al negoci tèxtil. Joan Brunes, deixà en herència el forn de vidre al seu fill, d'igual nom i ofici. A la mort d'aquest va ser la seva muller Beneta qui se'n féu càrrec. El testament del sogre és de novembre del 1623, el del marit data d'octubre de l'any següent ${ }^{106}$.

Una anotació dels censos del 5 de juliol del 1627, torna a parlar sobre el forn de vidre, en referir-se a la possessió per part de Beneta Brunes, vídua de Joan Brunes, d'un pont i dels habitatges annexos al forn de vidre situat al Pla d'en Llull, a Barcelona ${ }^{107}$.

Finalment, el 4 de juliol del 1646, Gabriel Brunes, fill de Joan Brunes, renuncia a la facultat concedida pel Patrimoni Reial de l'establiment del forn de vidre del Pla d'en Llull de Barcelona ${ }^{108}$.

${ }^{101} \mathrm{AHCB}$, Consell de Cent, Fogatges, XIX-30, f. s/n: 1496.

${ }^{102}$ AHCB, Consell de Cent, Fogatges, XIX-15, f. 51 v. - 52 r.

${ }^{103}$ ACA, Reial Patrimoni, Batllia, vol. 340, f. 29 v. (antiga numeració, f. 30 v.); vol. 343, f. 27 v.; vol. 344 , f. 28 v.; vol. 376 , f. 29 v.

${ }^{104}$ Parla de Magí Pellicer: ACA, Reial Patrimoni, Batllia, vol. 342, f. 8 r. Ho fan de Bartomeu Narbonès: ACA, Reial Patrimoni, Batllia, vol. 343 f. 8 v. i f. s/n; vol. 344 f. 6 v.; vol. 347 f. $10 \mathrm{v}$.; vol. 348 , f. s/n i vol. 1142, f. 51 v. En el darrer document (de 1586) paga el cens en dos cops,' 9 sous i 3 sous.

${ }^{105}$ Sobre Magí Pellicer: ACA, Reial Patrimoni, Batllia, vol. 349, f. s/n i vol. 326, f. 20 r. Sobre la possessió dels Brunes: ACA, Reial Patrimoni, Batllia, vol. 352, f. 49 v.

${ }^{106}$ ACA, Reial Patrimoni, Batllia, vol. 752, f. 292 r.

${ }^{107}$ ACA, Reial Patrimoni, Batllia, vol. 154, f. 2 r.

${ }^{108}$ ACA, Reial Patrimoni, Batllia, vol. 752, f. 292 r.; esmentat també al vol. 544, f. 118 r., i al vol. 352 , f. 49 v. 


\subsection{Tancament del forn del Pla d'en Llull}

De fet, la renúncia dels Brunes mostra la fi del privilegi i, amb ella, la fi del forn, que sembla que ja no era actiu des de feia un temps. Se sap, malgrat això, que la producció barcelonina no s'aturà definitivament. Així, hi ha documentats alguns problemes entre la confraria dels vidriers i l'establiment de nous forns a la ciutat, com el cas de Felip Amiguet que fa referència a la producció del vidre a la ciutat de Barcelona i als privilegis de les confraries d'oficis ${ }^{109}$.

Per una altra banda, el forn de vidre de Barcelona perdurà en la memòria de la ciutat. Així, l'any 1669, els cartoixans de la Beata Maria de Montalegre, de la diòcesi de Barcelona, establiren un contracte d'emfiteusi amb Lluís Pau Sentís, sastre de Barcelona, que incloïa tota la casa amb tres portals, més un altre al carrer, que tenia dit convent a la ciutat de Barcelona al lloc anomenat el Pla d'en Llull, davant el Rec Comtal, lloc que popularment es deia el "Forn del Vidre Vell" i que en aquell moment, segons diu el document, era també referit com "de les Triperies" Francesc Conca, moliner de Barcelona i Josep Enric, corder i esparter de Barcelona, intervingueren en un document sobre unes obres que s'havien encarregat al mestre de cases Josep Giralt i que es realitzaven en una casa situada a Barcelona en el "vico vocato del Forn del Vidre, sive den Pujalt, alies de las Triperas" al Pla d'en Llull ${ }^{111}$.

\section{CONCLUSIÓ}

Com s'ha vist, la producció barcelonina de vidre tingué una importància cabdal en època medieval i es perllongà durant molts anys. Els seus forns oferien produccions variades tant en tipus de vidre com en qualitats. Les concessions reials destacaren l'alta productivitat i la qualitat de les peces de vidre fetes a la ciutat. Entre les obres realitzades, cal destacar les feines esmaltades, de les quals avui es conserven encara bons exemples en alguns dels nostres museus. L'exclusivitat del forn de vidre de Barcelona - primer el de Viladalls i després el del Pla d'en Llull- va ser una constant des del darrer terç del segle XIV fins a mitjan segle XVII. Tot i així, existiren alguns intents de trencar aquesta exclusivitat, intents que, d'altra banda, tingueren una ràpida rèplica per part d'aquells que tenien el privilegi de

${ }^{109} \mathrm{AHCB}$, Consell de Cent. Registre de deliberacions, II-136 (1626-1627), ff. $46 \mathrm{v} .-47 \mathrm{r} . \mathrm{i}$ v., 117 v.-118 r. i v.; 129 v.-130 r. i v., 153 v.-154 r. i v., 165 v.-166 r.; AHCB, Consell de Cent. Registre de deliberacions, II-137 (1627-1628), ff. 9 v.- 10 r. i v., 12 r. i v.-13 r.

${ }^{110}$ AHPB, Jacint BoRRÀs, "Manual" any 1669, f. 907 r.: 4-novembre-1669.

${ }^{111}$ AHPB, Guillem Bosom, "21 manuale contractuum et instrumentorum" anys 1715-16 f. 73 r.: 3-abril-1716. 
634 SÍLVIA CAÑELLAS MARTÍNEZ; M. CARME DOMÍNGUEZ RODÉS

l'explotació del forn. Negoci i producció artística anaren de la mà en una manufactura que tingué un ampli ressò en el nostre entorn.

Data de recepció de l'article: maig 2008.

Data d'acceptació i versió final: juliol 2008. 


\begin{tabular}{|c|c|c|c|}
\hline \multicolumn{4}{|c|}{$\begin{array}{c}\text { Forn de vidre de Viladalls } \\
\text { Barcelona }\end{array}$} \\
\hline Dates & Propietari & Concessions & Altres fets \\
\hline 1316 & $\begin{array}{l}\text { Guillem Barceló, de } \\
\text { Barcelona, vidrier }\end{array}$ & $?$ & $\begin{array}{l}\text { Lloc desconegut. } \\
\text { Problemes amb la } \\
\text { llenya. }\end{array}$ \\
\hline 1325 & $\begin{array}{l}\text { Guillem Barceló, } \\
\text { vidrier }\end{array}$ & $?$ & $\begin{array}{l}\text { Únic posseïdor de } \\
\text { forn de vidre a } \\
\text { Barcelona. }\end{array}$ \\
\hline 1331 & $\begin{array}{l}\text { Guillem Barceló, } \\
\text { vidrier }\end{array}$ & $\begin{array}{l}\text { El rei referma la concessió del forn de vidre. No } \\
\text { pot cremar més de tres somades de llenya/dia. }\end{array}$ & \\
\hline 1340 & $\begin{array}{l}\text { Guillem Barceló, } \\
\text { vidrier }\end{array}$ & $\begin{array}{l}\text { El permís és hereditari. Poden consumir fins a } \\
\text { quatre somades de llenya/dia. }\end{array}$ & $\begin{array}{l}\text { Continua sent l'únic } \\
\text { forn de la ciutat. }\end{array}$ \\
\hline (1346) & $\begin{array}{l}\text { (Bernat Desmunt, } \\
\text { vidrier) }\end{array}$ & $\begin{array}{l}\text { (Establiment d'un segon forn de vidre amb } \\
\text { permís del rei i del Consell de Cent de } \\
\text { Barcelona). }\end{array}$ & \\
\hline 1370 & $\begin{array}{l}\text { Pere Barceló, fill de } \\
\text { Guillem Barceló, } \\
\text { vidriers }\end{array}$ & $\begin{array}{l}\text { Renovació de la concessió a perpetuïtat. } \\
\text { Exclusivitat. Elogis del rei a la feina que es feia } \\
\text { al forn. Es podia també coure vidre i fer } \\
\text { vaixelles o altres artificis de vidre. }\end{array}$ & \\
\hline-- & $\begin{array}{c}\text { Bernat Barceló, } \\
\text { vidrier }\end{array}$ & -- & -- \\
\hline \multirow[t]{2}{*}{1394} & $\begin{array}{l}\text { Francesca, vídua de } \\
\text { Bernat Barceló, } \\
\text { vidrier }\end{array}$ & $\begin{array}{l}\text { Renovació i ampliació: } \\
\text { • passa de tres a quatre obralls, } \\
\text { • a les quatre somades de llenya grossa/dia se } \\
\text { n'afageixen quatre de llenya petita. }\end{array}$ & \\
\hline & Miquel Çabastida & & \\
\hline $1436-59$ & $\begin{array}{l}\text { Ramon Lleonard } \\
\text { Derç, barber }\end{array}$ & & $\begin{array}{l}\text { Pagament dels } \\
\text { censos anuals. }\end{array}$ \\
\hline 1453 & $\begin{array}{l}\text { Elionor, esposa de } \\
\text { Joan Bach i filla de } \\
\text { Ramon de } \\
\text { Villarrohir, especier }\end{array}$ & & $\begin{array}{l}\text { Pagament del cens } \\
\text { anual. Menció del } \\
\text { forn del Pla d'en } \\
\text { Llull, concedit a } \\
\text { Bartomeu Llorenç. }\end{array}$ \\
\hline 1463 & $\begin{array}{l}\text { Ramon Lleonard } \\
\text { Derç, barber }\end{array}$ & & $\begin{array}{l}\text { Problemes de } \\
\text { solvència. }\end{array}$ \\
\hline 1482 & $\begin{array}{l}\text { Francina, hereva } \\
\text { d'Elionor, vídua de } \\
\text { Joan Derç, coraler }\end{array}$ & $\begin{array}{l}\text { Venda de la concessió al brodador Antoni } \\
\text { Sadurní. }\end{array}$ & $\begin{array}{l}\text { El coraler Joan } \\
\text { Derç era l'hereu de } \\
\text { Ramon Lleonard } \\
\text { Derç, barber. }\end{array}$ \\
\hline $1484-89$ & $\begin{array}{l}\text { Antoni Sadurní, } \\
\text { brodador }\end{array}$ & & $\begin{array}{l}\text { Paga els censos, } \\
\text { però no pot refer el } \\
\text { forn. }\end{array}$ \\
\hline
\end{tabular}




\begin{tabular}{|c|c|c|c|}
\hline \multicolumn{4}{|c|}{ Forn de vidre de Mallorca } \\
\hline Dates & Propietari & Concessions & Altres fets \\
\hline 1352 & $\begin{array}{l}\text { Guillem Bartomeu, } \\
\text { de Barcelona, } \\
\text { vidrier }\end{array}$ & $\begin{array}{l}\text { Concessió per fer un forn. Podia fer-lo i refer-lo } \\
\text { on volgués, dins la ciutat de Mallorca, per tal } \\
\text { de fer obra en vidre. }\end{array}$ & $\begin{array}{l}\text { Comentari sobre la } \\
\text { llenya de l'Illa. }\end{array}$ \\
\hline \multicolumn{4}{|c|}{ Forn de vidre de Badalona } \\
\hline 1360 & $\begin{array}{c}\text { Francesc } \\
\text { d'Aversone, ciutadà } \\
\text { de Barcelona, } \\
\text { vidrier }\end{array}$ & $\begin{array}{l}\text { Concessió per tenir ell i els seus successors, un } \\
\text { forn de vidre a perpetuïtat. Podia obrar } \\
\text { qualsevol feina en vidre i vendre o arrendar la } \\
\text { concessió. }\end{array}$ & \\
\hline \multicolumn{4}{|c|}{ Forn de vidre de Sant Pere de Bigues } \\
\hline 1407 & $\begin{array}{c}\text { Francesc Ça Torra, } \\
\text { vidrier }\end{array}$ & & $\begin{array}{l}\text { Carta de ciutadania } \\
\text { de Barcelona. }\end{array}$ \\
\hline 1423 & Pere Pujalt, vidrier & & $\begin{array}{l}\text { Carta de ciutadania } \\
\text { de Barcelona. }\end{array}$ \\
\hline 1505 & $\begin{array}{l}\text { Francesc Granada, } \\
\text { vidrier }\end{array}$ & & $\begin{array}{l}\text { Arrendament del } \\
\text { forn al vidrier } \\
\text { Jaume Çavertés. }\end{array}$ \\
\hline \multicolumn{4}{|c|}{ Forn de vidre de Sant Vicenç de Vallromanes } \\
\hline 1429 & Pau Sala, vidrier & & $\begin{array}{l}\text { Aprenentatge } \\
\text { d'Andreu Baldoni. }\end{array}$ \\
\hline 1432 & Pau Sala, vidrier & & $\begin{array}{l}\text { Aprenentatge de } \\
\text { Bernat Jonquers. }\end{array}$ \\
\hline 1455 & Pau Sala, vidrier & & $\begin{array}{l}\text { Deutes amb } \\
\text { Francesc Clot, } \\
\text { vidrier. Un serf } \\
\text { captiu treballava al } \\
\text { forn. }\end{array}$ \\
\hline 1458 & $\begin{array}{l}\text { Joan Sala, fill de } \\
\text { Pau Sala, vidrier }\end{array}$ & & $\begin{array}{l}\text { Pau Sala és mort. } \\
\text { La vídua arrenda } \\
\text { les propietats. }\end{array}$ \\
\hline \multicolumn{4}{|c|}{ Forns de vidre de Montcada } \\
\hline 1486 & $\begin{array}{l}\text { Antoni Sadurní, } \\
\text { brodador, i Jaume } \\
\text { Granada, vidrier }\end{array}$ & $\begin{array}{l}\text { Demanda i resolució del Consell de Cent de } \\
\text { Barcelona sobre la instal·lació del forn. }\end{array}$ & \\
\hline 1489 & Vicenç Sala, vidrier & Nou forn de vidre. & \\
\hline 1404 & $\begin{array}{c}\text { Vicenç, Joan i Pau } \\
\text { Sala }\end{array}$ & & $\begin{array}{l}\text { Propietats a } \\
\text { Montcada. }\end{array}$ \\
\hline
\end{tabular}




\begin{tabular}{|c|c|c|c|}
\hline \multicolumn{4}{|c|}{ Forn de vidre del Pla d'en Llull, Barcelona } \\
\hline Dates & Propietari & Concessions & Altres fets \\
\hline$(1448)$ & $\begin{array}{c}\text { (Bartomeu Llorenç, } \\
\text { vidrier de } \\
\text { Barcelona) }\end{array}$ & ---- & $\begin{array}{l}\text { Fill de Gispert } \\
\text { Llorenç, vidrier. }\end{array}$ \\
\hline 1453 & $\begin{array}{l}\text { Bartomeu Llorenç, } \\
\text { vidrier }\end{array}$ & $\begin{array}{l}\text { Llicència de forn on fer recipients de vidre dins } \\
\text { Barcelona. Possibilitat de modificació i } \\
\text { reconstrucció del forn, però cal mantenir-lo } \\
\text { sempre en peu. Exclusivitat. Inactivitat màxima: } \\
\text { dos mesos. }\end{array}$ & \\
\hline 1454 & $\begin{array}{l}\text { Bartomeu Llorenç, } \\
\text { vidrier }\end{array}$ & & $\begin{array}{l}\text { Deute per compra } \\
\text { de sosa. }\end{array}$ \\
\hline $1461-63$ & $\begin{array}{l}\text { Bartomeu Llorenç, } \\
\text { vidrier }\end{array}$ & & $\begin{array}{l}\text { Aprenentatge } \\
\text { d'Esteve Granada }\end{array}$ \\
\hline 1464 & $\begin{array}{l}\text { Bartomeu Llorenç, } \\
\text { vidrier }\end{array}$ & & $\begin{array}{l}\text { Petició d'exonera- } \\
\text { ció impost llenya. }\end{array}$ \\
\hline 1473 & $\begin{array}{l}\text { Bartomeu Llorenç, } \\
\text { vidrier }\end{array}$ & $\begin{array}{l}\text { Problemes de competència: forn de Ponç Julià. } \\
\text { Reacció: renovació i ampliació de l'exclusiva a } \\
\text { totes les feines en vidre i a dues llegües entorn } \\
\text { Barcelona, llibertat en la quantitat d'obralls, } \\
\text { possible inactivitat d'un any per guerra. }\end{array}$ & $\begin{array}{l}\text { Crida pública. } \\
\text { Ordre } \\
\text { d'enderrocament } \\
\text { del forn de Ponç } \\
\text { Julià. }\end{array}$ \\
\hline 1477 & $\begin{array}{l}\text { Bartomeu Llorenç, } \\
\text { vidrier }\end{array}$ & Renovació de l'establiment. & \\
\hline 1484 & $\begin{array}{l}\text { Bartomeu Llorenç, } \\
\text { vidrier }\end{array}$ & & $\begin{array}{l}\text { Revisió de l'impost } \\
\text { de la llenya }\end{array}$ \\
\hline 1493 & $\begin{array}{l}\text { Mateu Llorenç, } \\
\text { vidrier }\end{array}$ & Recordatori de les concessions. & \\
\hline 1497 & $\begin{array}{l}\text { Mateu Llorenç, } \\
\text { vidrier }\end{array}$ & $\begin{array}{l}\text { Renovació amb repàs de privilegis. Ampliació a } \\
\text { tot Catalunya. Producció de vidres esmaltats. }\end{array}$ & \\
\hline $1506-17$ & $\begin{array}{l}\text { Francesc Trauer, } \\
\text { mercader }\end{array}$ & $\begin{array}{l}\text { (Entre 1506-10 el forn és arrendat a Damià } \\
\text { Granada i Joan Cornet, vidriers) }\end{array}$ & Cens del forn. \\
\hline 1535 & $\begin{array}{l}\text { Elisabet, muller de } \\
\text { Feliu Pons }\end{array}$ & $\begin{array}{l}\text { Venda de la concessió al vidrier Bartomeu } \\
\text { Narbonès. }\end{array}$ & $\begin{array}{l}\text { Feliu Pons era de } \\
\text { Mallorca }\end{array}$ \\
\hline $1553-76$ & $\begin{array}{l}\text { Bartomeu } \\
\text { Narbonès, vidrier }\end{array}$ & E1 forn tenia quatre obralls. & $\begin{array}{l}\text { (El cens de } 1566 \text { el } \\
\text { paga M. Pellicer) }\end{array}$ \\
\hline $1591-98$ & Magí Pellicer & & Pagament de cens \\
\hline $\begin{array}{l}1603- \\
1624\end{array}$ & $\begin{array}{l}\text { Joan Brunes (pare i } \\
\text { fill), negoci tèxtil }\end{array}$ & $\begin{array}{l}\text { Declaracions sobre la possessió del forn de } \\
\text { vidre }\end{array}$ & $\begin{array}{l}\text { Testaments } 1623 \\
\text { (pare) i } 1624 \text { (fill) }\end{array}$ \\
\hline 1627 & $\begin{array}{l}\text { Beneta, vídua de } \\
\text { Joan Brunes }\end{array}$ & $\begin{array}{l}\text { Declaracions sobre possessions relacionades } \\
\text { amb el forn de vidre }\end{array}$ & $\begin{array}{l}\text { Habitatge familiar } \\
\text { annex al forn }\end{array}$ \\
\hline 1646 & Gabriel Brunes & Renúncia al privilegi. & Fill de Joan Brunes \\
\hline
\end{tabular}

